\title{
Finite Element Analysis of Static and Dynamic Characteristic on the Turnover Device Main Spindle of Aluminum Ingot Stacker Based on ANSYS WORKBENCH*
}

\author{
Rui Zhi-yuan ${ }^{1, a}$, Zhou Yin-cheng ${ }^{1, b}$, Liu Jun ${ }^{1, c}$ \\ ${ }^{1}$ School of Mechanical Engineering,Lanzhou University of Technology,Lanzhou 730050,China

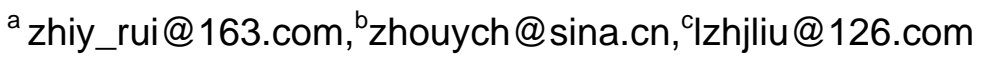

Key words: dynamic characteristic, finite element method, modal analysis

\begin{abstract}
On the basis of kinematics analysis, the relationship of torque on the main spindle of the aluminum ingot stacker turnover device dependent on angle is discussed. Moreover, the static and dynamic characteristics of the main spindle, whose static deformation can be obtained and whose torsion rigidity can be calculated, were researched by the finite element method. After the model analysis on main spindle, the inherent frequency and vibration mode of its first five orders are acquired, which can constitute the evidence to improve its dynamic characteristic.
\end{abstract}

\section{Introduction}

The static and dynamic characteristics of the whole machine are mainly determined by the main spindle system. The vibration, which can lead to the loud noise, occurred during working process. The components of the main spindle will be severely damaged, its dynamic load will be increased and its lifespan and precision will be reduced in case of resonance [1].

\section{Kinematic analysis on the main spindle of the turnover device}

The average turnover time totals $1.6 \mathrm{~s} / \mathrm{block}$ in a cycle process of turnover, according to the throughput of $22 \mathrm{t} / \mathrm{h}$ aluminum ingot continuous casting line. The clamping block and aluminum ingot undergo acceleration, uniform and deceleration in the whole process. Suppose the acceleration and deceleration process is uniform, the acceleration time is $0.1 \mathrm{~s}$, the uniform time is $1.2 \mathrm{~s}$ and the deceleration time is $0.3 \mathrm{~s}$. The flip trip is $180^{\circ}$.

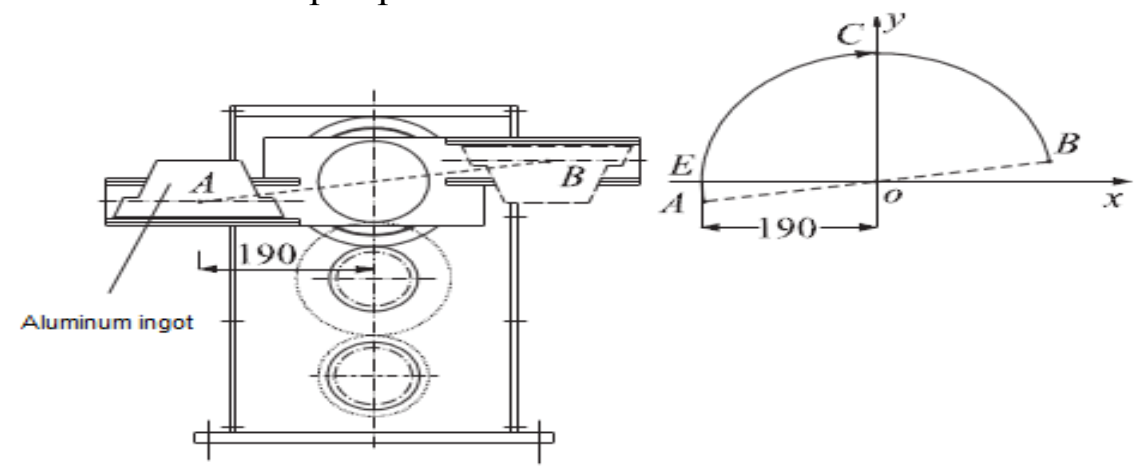

Fig.1 The structure drawing of aluminum ingot turnover device

The components of the turnover device will be greatly impacted by the inertia moment, which is produced by aluminum ingot and clamping blocks during the turnover process. Seen from the coordinate system in figure 1 above, the loads applied on the main spindle have been obtained by the equations as follows:

The load moment produced by Gravity:

*Technology Support Program 1011GKCA007

The national natural Fund 51,265,032

National international science and technology cooperation projects 2011DFR70670 


$$
\mathrm{T}_{1}=\left(\mathrm{m}_{1}+2 \mathrm{~m}_{2}\right) \mathrm{gr} \cdot \cos \theta \quad\left(-9^{\circ} \leq \theta \leq 171^{\circ}\right)
$$

The inertia moment produced in the acceleration phase:

$\mathrm{T}_{2}=\left(\mathrm{m}_{1}+2 \mathrm{~m}_{2}\right) \varepsilon_{1} \mathrm{r}_{2} \quad\left(-9^{\circ} \leq \theta \leq-2.5^{\circ}\right)$

The inertia moment produced in the deceleration phase:

$\mathrm{T}_{3}=-\left(\mathrm{m}_{1}+2 \mathrm{~m}_{2}\right) \varepsilon_{2} \mathrm{r}_{2} \quad\left(152.5^{\circ} \leq \theta \leq 180^{\circ}\right)$

The moment of inertia from each gear in the gear box:

$\mathrm{T}_{4}=2\left(\mathrm{~J}_{\mathrm{a}} \varepsilon_{\mathrm{a}}+\mathrm{J}_{\mathrm{b}} \varepsilon_{\mathrm{b}}+\mathrm{J}_{\mathrm{c}} \varepsilon_{\mathrm{c}}\right)$

The total torque in the main spindle:

$\mathrm{T}_{\mathrm{L}}=\mathrm{T}_{1}+\left(\mathrm{T}_{2} / \mathrm{T}_{3}\right)+\mathrm{T}_{4} / \eta$

In these equations: $m_{1}$ is the mass of the aluminum ingot. $m_{2}$ is the mass of the clamping block. $\mathrm{J}_{\mathrm{a}}, \varepsilon_{\mathrm{a}}, \mathrm{J}_{\mathrm{b}}, \varepsilon_{\mathrm{b}}, \mathrm{J}_{\mathrm{c}}, \varepsilon_{\mathrm{c}}$ are the inertia and the angular acceleration of each gear in the gear box. The mechanical efficiency $\eta$ is $90 \%$ [2] .

The torque can be obtained by the kinematic analysis. The torque with angle changing on the main spindle is shown in table 1.

Table1. Torque with Angle changing

\begin{tabular}{|r|r|r|r|r|}
\hline$\theta^{\circ}$ & $-9^{\circ}$ & $-2.5^{\circ}$ & $90^{\circ}$ & $171^{\circ}$ \\
\hline $\mathrm{T}_{\mathrm{L}}[\mathrm{N} \cdot \mathrm{m}]$ & 120 & 123 & 0 & 103 \\
\hline
\end{tabular}

\section{The finite element analysis of the main spindle}

\section{Established the main spindle model}

The main spindle system of the turnover device is made up of gear spindle, positioning shaft of the clamping block, clamping block, screw and bearing. Its structural diagram is shown in figure 2 . Most of the force and torque are undertaken by the main spindle. Therefore, in order to improve the efficiency of the turnover device, reduce its noise and conduct smooth operation, it is essential to know the dynamic characteristic of main spindle through dynamic analysis.

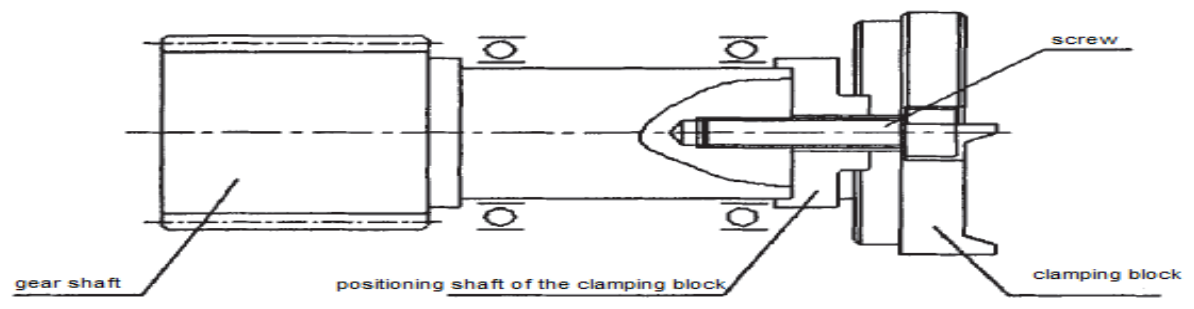

Fig.2 Turnover device main spindle structure diagram

Gear spindle modulus $\mathrm{m}=4 \mathrm{~mm}$, number of teeth $\mathrm{z}=24$, pressure Angle $\alpha=20^{\circ}$ tooth width $\mathrm{B}$ $=50 \mathrm{~mm}$, axial length $240 \mathrm{~mm}$. The three-dimensional model of the main spindle was built according the actual size by the Pro/E. The three-dimensional model was invoked in ANSYS WORKBENCH and carried on the grid automatic division [3].

The static deformation analysis

Linear static structural analysis is used to analyze the response, caused by the static load applied on the structure. In the classical mechanics theory, the object dynamics general equation is applied:

$[\mathrm{M}]\{\ddot{\mathrm{x}}\}+[\mathrm{C}]\{\dot{\mathrm{x}}\}+[\mathrm{K}]\{\mathrm{x}\}=\{\mathrm{F}\}$

In the linear static analysis of structures, all items related to time are ignored. So Eq. (7) can be get from Eq. (6):

$[\mathrm{K}]\{\mathrm{x}\}=\{\mathrm{F}\}$

Static structural analysis system was chosen from the WORKBENCH to analyze the static deformation of the main spindle. Material of the main spindle is 45 steel and the material parameters are shown in table 2. In supporting and housing connected part, all degrees of freedom 
were limited, then the front end of the main spindle was fixed and the equivalent torque was added to the gear end. The results of the ANSYS analysis and calculation of static deformation are shown in figure 3.

Table 2 the main material parameters

\begin{tabular}{|l|c|c|c|}
\hline Parameter & Elastic modulus $[\mathrm{N} / \mathrm{m}]$ & Poisson ratio & Density $\left[\mathrm{kg} / \mathrm{m}^{3}\right]$ \\
\hline Value & $2.01 \mathrm{e}+11$ & 0.3 & 7800 \\
\hline
\end{tabular}

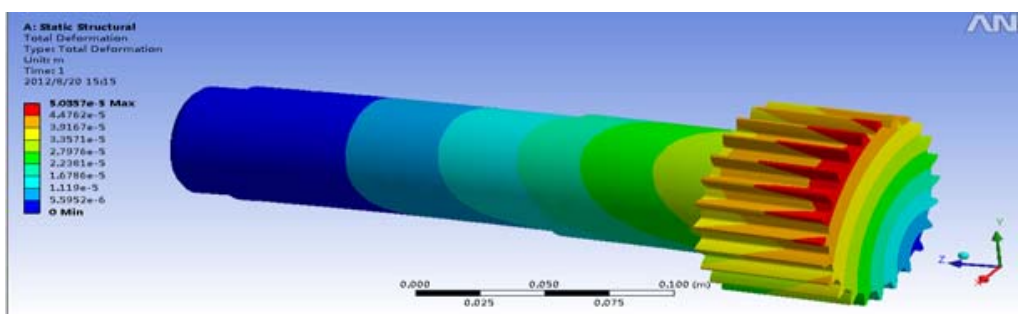

Fig.3 The main spindle static deformation

From the graph above, the deformation of spindle gear end, caused by the torque, was perceived. The largest deformation is in loading place. The other tooth deformations gradually decrease from the loading tooth to other teeth [4]. The largest deformation displacement is $0.050357 \mathrm{~mm}$. The main spindle torsion rigidity can be calculated in the equation below:

$$
K=\frac{\omega}{\sigma}=0.45 \times 10^{4} \mathrm{~N} \cdot \mathrm{m}^{2} / \mathrm{rad}
$$

\section{The modal analysis}

Modal analysis is an important link in dynamics analysis and is used to analyze the structure of the natural frequency and vibration mode. It is the foundation of other dynamics analysis, such as transient dynamics analysis, harmonic response analysis and spectrum analysis [5]. From the modal analysis, vibration frequency $\omega_{i}$ and modal $\phi_{i}$ can be calculated by the equation:

$$
\left([\mathrm{K}]-\omega_{\mathrm{i}}^{2}[\mathrm{M}]\right)\left\{\phi_{\mathrm{i}}\right\}=0
$$

Because the axial rigidity of the main spindle is very big and the influence of damping on transverse vibration characteristics is small, only radial stiffness influence is considered when establishing finite element model. During the modal analysis, the bearing is replaced by elastic supports. Unit and grid division is same to the static analysis. In the postprocessor of workbench, the inherent frequency and vibration model can be obtained by modal analysis of the main spindle, as shown in table 3 for the first five orders natural frequency and as shown in figure 4 - figure 8 for the first five orders deformation diagram. The critical speed of each order can be calculated by the formula below:

$$
\begin{gathered}
\mathrm{n}_{\mathrm{i}}=60 \omega_{\mathrm{i}} / 2 \pi \\
\mathrm{f}_{\mathrm{i}}=\omega_{\mathrm{i}} / 2 \pi
\end{gathered}
$$

Table 3 first five orders natural frequency

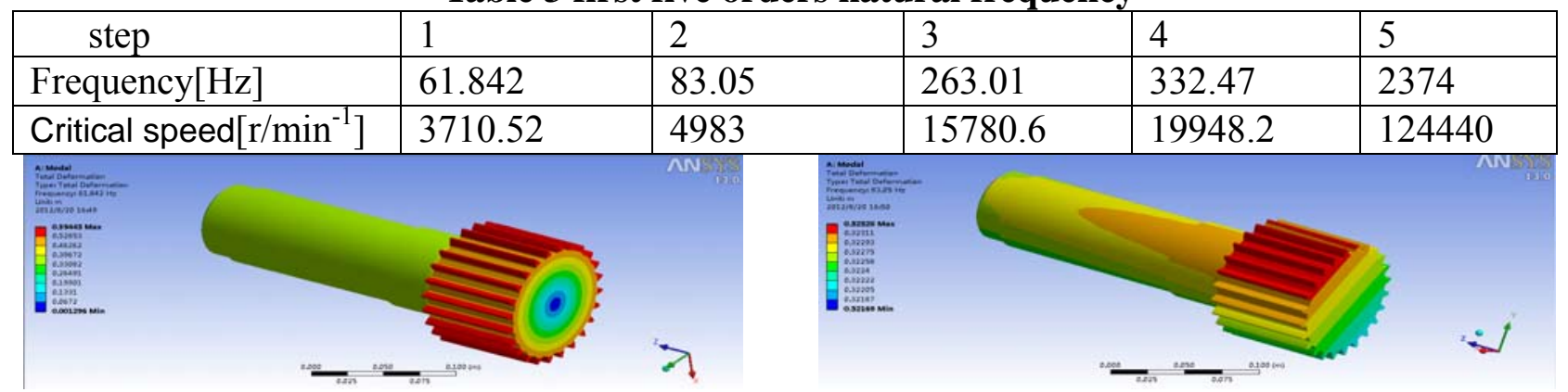

Fig.4 The first order vibration mode

Fig.5 The second order vibration mode 


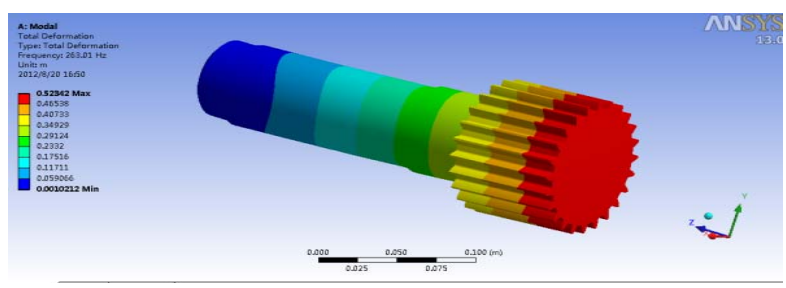

Fig.6 The third order vibration mode

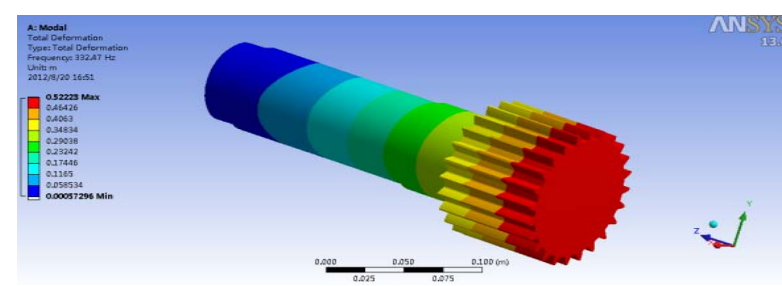

Fig.7 The forth order vibration mode

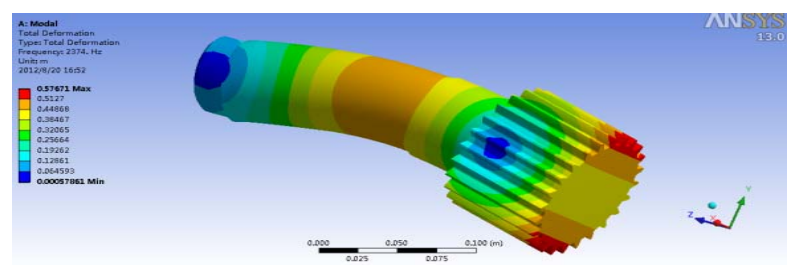

Fig.8 The fifth order vibration mode

Table 2 showed that the lowest inherent frequency of the main spindle was $61.842 \mathrm{HZ}$. The working speed of the turnover device is far slower than the critical speed of the main spindle. So it can be considered that the stacking machine could not induce resonance within its natural working speed [6]. As shown in Fig.4-8, main spindle mainly suffers torsional deformation. In vibration mode of each order, the maximum amplitude is in the gear end and the minimum amplitude is in the support. It can be sure that the vibration of main spindle system for each order modal is in accordance with the changing rule of the each point amplitude. The inherent frequency and vibration model provide the reliable numerical basis for us to improve the dynamic performance of structure [7].

\section{Concluding remarks}

The finite element model of the turnover device main spindle is established in this paper. And its statics and dynamics characteristics are analyzed by general finite element software ANSYS WORKBENCH. And then, the static deformation of the main spindle is obtained and the rigidity if it is calculated. Meanwhile, the frequency of the first five orders as well as the vibration mode of each order of the main spindle is acquired through the modal analysis on it. After the static and dynamic analysis on the main spindle, its dynamic characteristics can be understood, which provide sound numerical basis for the stable, high efficient and low noise work of the turnover device.

\section{References}

[1] RUI Zhi-yuan, SHANG Yi-cun, Dynamic Performance Analysis of the Aluminum Ingot Stacker Based on ANSYS. Modular Machine tool \& Automatic Manufacturing, 2008(4):27-29

[2] XIE Dong-dong,LI E-min,ZHANG Ming,GAO Chang-hong, The design of hydraulic system for $22 \mathrm{t} / \mathrm{h}$ aluminum ingot turnover mechanism. Chinese Hydraulics \& Pneumatics, 2011, (11):87-89

[3] CHEN Yu-yu. Research on Torsional Vibration Characteristics of the Key Parts of Aluminum ingot Stacker the Tipping Gear. Machine Building \& Automation, 2009, 2:53-54

[4] LUO De-chun, ZHANG Lin, YU Tao, RUI Zhi-yuan. The dynamic characteristics analysis for the backbone of the buck stacker of aluminum ingot. Machinery Design \& Manufacture, 2010, 2:188-190

[5] CHEN Yu-yu. Research on Dynamic Characteristics of the Key Parts of Aluminum ingot Stacker. Ph M Thesis. Lanzhou: Lanzhou University of Technology.2007 (in Chinese)]

[6] SHANG Yi-cun .The dynamic characteristics analysis for the buck stacker of aluminum ingot. Ph M Thesis. Lanzhou: Lanzhou University of Technology, 2008 (in Chinese)

[7] CHEN Guo-rong, TANG Shao-hua, Dynamic finite element analysis on spindle of vibratory motor. Modern Manufacturing Engineering, 2009, 12:54-59 